\title{
THE ROLE OF COMMUNICATION IN ENHANCING WORK EFFECTIVENESS OF AN ORGANIZATION
}

\author{
George BUCĂŢA \\ "Lucian Blaga" University, Sibiu, Romania \\ george.bucata@yahoo.ro \\ Alexandru Marius RIZESCU \\ "Nicolae Bălcescu” Land Forces Academy, Sibiu, Romania \\ mariusrizescu@yahoo.com
}

\begin{abstract}
Communication is one of the most important levers of management that a company can implement for the formation of teams and achieving valuable performance. Communication and management are complementary disciplines and strong business elements for success. Management skills are essential in a business, but all equally important are those relating to the rules for the communication and the way in which a manager knows how to interact with his staff. Being manager not only means to rein in business, but mostly means knowing to coordinate a team, leadership skills and most of all, communicate.
\end{abstract}

KEYWORDS: business communication, organizational communication, work productivity

\section{Introduction}

It is essential that any type of organization, which wishes to pursue an activity in full accordance with the society in which it exists, to begin the work based on a pre-set plan, a management strategy carefully designed as management represents a vital aspect of the functioning of the organizational and the social systems, especially in the conditions of modern era, marked by the increasing complexity of technological and informational products, radical transformation at the level of social structure, trends of globalization of the economy and, especially, changes to the product at the organizational level. In this context we consider necessary the intervention of managerial structures that will adapt to all organization changes.

\section{Internal Corporate Communication Process \\ Management should consider first people. The main aim of their involvement in the tasks they have undertaken, the efficiency with which they are carried out as it is a very important parameter, bearing especially in mind that it requires management to work together in teams. Management deals with the coordination of their activities, planning, organization and coordination of pre-established objectives,}


levels, budget management and control and assessments, as a result of the work carried out. These management functions which support work within the organization are bringing a touch of its dynamism. The individuals of the organization, namely the work force, will be the first to benefit from the results of the strategy or not, because they are the ones who execute the tasks assigned to attain the objectives (Bodie and Crick, 2014).

Therefore, a manager who is in charge of carrying out the functions of management will always use the processes of communication in order to make it understandable to coordinate its business activities, to make decisions and implement them, in order to conclude partnership and cooperation agreements etc. Communication, from a management point of view, is the process by which people are informed and guided to achieve the best results. To communicate effectively means not only putting your thoughts in order and presenting them in an accessible way, but also expressing them in a way that would capture the attention of the receiver (Beattie and Ellis, 2014).

Communication makes possible the interaction between members of the working team. A manager should be the first to establish bridges between the members of the organization, through a careful and effective communication. Through communication, organization activities scroll correctly. A good manager will use communication in order to make it understandable to convey its message receptor exactly as we think in order to obtain the expected feedback at the time of the initiation of the communicative process. All these elements form the basis of communication processes, whereby individuals of an organization will be able to establish interpersonal connections, which are be the basis of good management activities, both internally and externally.

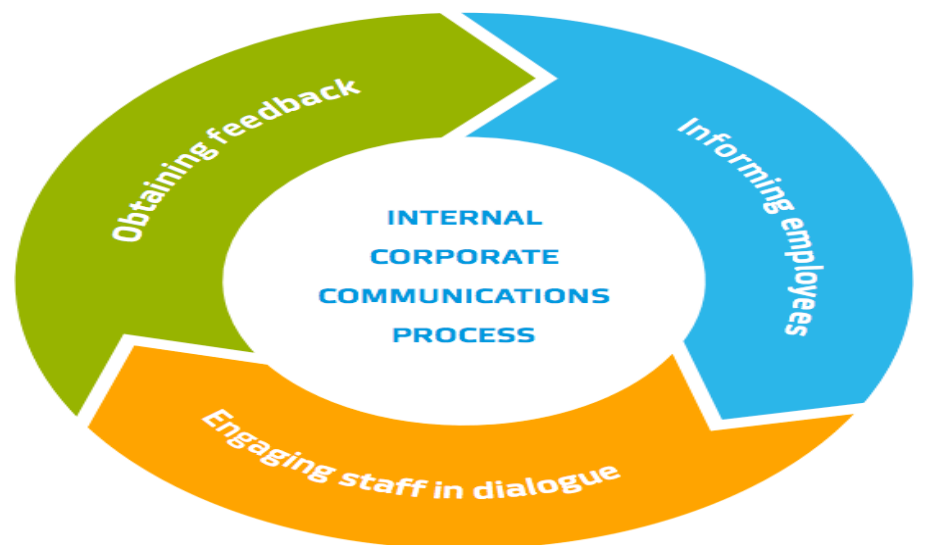

Figure no. 1 The internal corporate communications process

(Source: Miller, 2012)

As a management tool, communication intends to establish good interpersonal relationships, non-confrontational and based on the achievement of common goals: to increase the level of skills, the need to mobilize employees on the path of changing goals, in order to exploit to the fullest of their work force the evolution of forms of production. It resembles some of the factors that could explain the objective of increasing the role of communication.
Managerial communication must take into account a number of conditions:

- a concise and precise formulation of the message to be understood easily and in full;

- rapid transmission of the message;

- fluency and assurance of reversibility of communication;

- use of a common language of the transmitter and receiver; 
- simplifying the communication channels;

- ensuring flexibility and adaptability of the system of communication to be used in any situation (Burnside-Lawry, 2011).

Only effective communication can enable the successful completion of these requirements, which are necessary for conducting tool organization. According to some authors, communication management is a form of interpersonal leadership, a tool with which the manager may exercise specific powers: forecasting, training, organization, coordination, control, evaluation. According to these boundaries of communication management, the manager can arrange tasks in a more efficient manner, he can communicate more easily with employees, have a starting point in making decisions, a well developed plan.

Furthermore, the managerial communication has a triple role:

- Interpersonal role: managers act as leaders of the organization, interacting with peers, subordinates, customers from the organization and from outside. Specialized studies mention that managers use about $45 \%$ of the time for communication, in discussions with colleagues at the same hierarchical level, $45 \%$ communicating with employees in their organization and only $10 \%$ of the time, to communicate with superiors.

- Informational role, whereby managers collected information from colleagues, from subordinates and through other contacts, trying to keep themselves informed about anything that might affect their work and responsibility. Also, they in turn, disseminate, and provide important information.

- The role of decision-making: managers implement new projects, allocate resources on individuals and work compartments within the organization. Some of the decisions are taken in private, but they are based on information that has been disclosed before.

Analyzing the three roles, a common result is obtained, namely the importance of communication in the organization without which things might not work. Lack of communication may cause certain problems to achieving the objectives of the company.

Employees are the most important resource of the organization, and the way in which they are actively involved in attaining the strategic objectives of the company for which they work is crucial to get the expected performance of top management (Kandlousi et al. 2010).

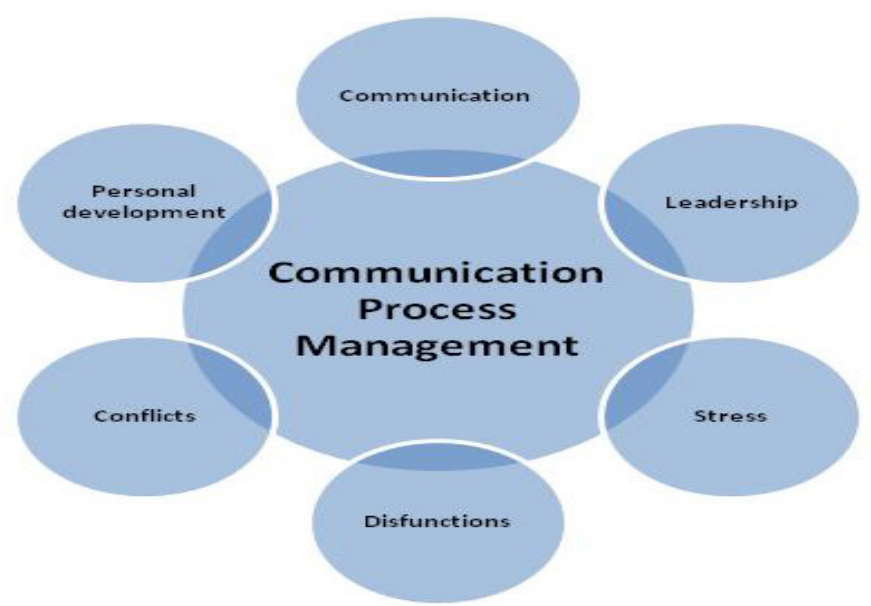

Figure no. 2 Communication Process Management

(Source: Beattie, \& Ellis, 2014) 


\section{Communication Process Management \\ The motivated and dedicated} employees are the dream of any employer because they are the ones that increase the productivity of the company, maintain a positive working environment and based on collaboration and teamwork, are loyal to the company. In short, they are the ones who ensure the long-term success of the organization (Frandsen, Johansen and Pang, 2013).

Motivating employees, however, is not an easy thing to get. Motivation, from the psychological point of view, is the basis of each individual's behavior, both in the sphere of personal and professional. When we talk about an employee's behavior at work, motivation has strict concerning the manner in which it perceives its role within the organization, with the way in which his work is appreciated, both in terms of value (the fact that he receives a salary for his work), and the social aspect (the way in which his work is regarded by others) but also with human relations established in the professional area.

In addition to human resource policies that are implemented in any organization in terms of financial packages, career plans, training programs and professional development, internal communication programs have a very important role in enhancing the motivation of employees. The explanation is simple: numerous studies have shown that, at the international level, great importance is given to the non-financial factors, such as: the relationship between professional life and private life and quality relationships with coworkers. Internal communication programs contain increasingly more often such factors of non-financial motivation.
Internal professional communication has been challenged over the last decade, gradually passing from the internal communication programs intended exclusively for the dissemination of information within the organization, whether uni-or bi-directional, to programs of involvement and motivation of employees (Miller, 2012).

In general terms, communication inside a company:

- creates job satisfaction: organizations that encourage a distribution of information between seniors and subordinates, as well as between employees of the same departments; a good feedback brings only benefits, motivates employees to work better and makes them feel valuable to the company; open communication prevents the occurrence of conflicts and helps solving them faster. When a conflict is resolved through discussion, employees develop mutual respect, which leads to an their development, both professionally and personally;

- grows productivity; effective communication in the workplace is an important issue for the success or failure of the organization; managers need to define, to explain thoroughly the objectives to be accomplished, communicate to employees the responsibilities and duties that have to be met; if the line ahead is clear, the employees will know exactly what they have to do and how to focus on that, leading to increased productivity;

- uses resources more effectively: when problems, crises and conflicts arise in an organization, due to the lack of communication between employees, unnecessary delays in the daily routine occur; it comes down to a resource leak and end up in decreasing the overall productivity. 


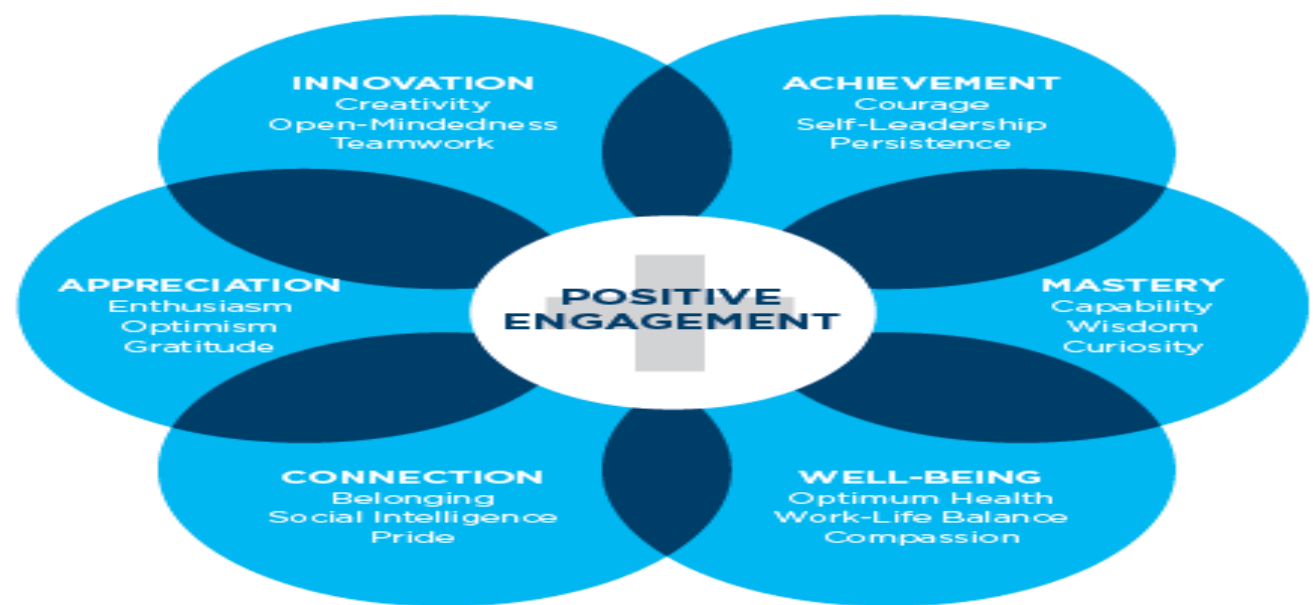

Figure no. 3 The positive engagement model (communication perspective)

(Source: Ruck \& Welch, 2012)

As leader or manager in an organization, the person in charge needs to make him/her understood, and to send the information to arrive at the receiver in time, in order to be processed; if it is lost then the fault will occur at the organizational level. Effective communication involves expressing the content and intention of the transmitter to the receiver provided that the receiver may have understood the message and that between receiver and transmitter there are certain differences. It is pointless using the mind to dominate the heart. We act more on the basis of what we feel instead of based on what we think. If employees do not maintain harmonious feelings among them, emotional barriers will appear. Communication is primarily a matter of confidence and acceptance of ideas and feelings of others. If we manage to leave aside the spirit of adversity, social norms, exaggerated attention to building their own images, we save a lot of energy and time. A large part of the decisionmaking process in the organization requires working in teams. Driving groups allows the purchase of information, information that is required for efficient management.

In this context, if the working party must act to be effective, it requires ensuring open communication between participants and the responsibility rests with the information flow in the largest part of the head of the group: the concern to inform the collaborators in the work and to inform them correctly, the ability to create conditions for all to be able to express themselves freely. In this sense, permissive position communication is expressed through the fact that it does not interfere with the stifling premature criticism of an opposite view, but also gives the possibility of discussion (Ledbetter, 2014).

This open attitude towards the dynamics of group discussion is not an instinctive human ability, but, on the contrary, it requires adequate training for those who have status and leadership responsibilities. Most problems encountered in the process of communication lies in the issues of credibility. Each sees the world through their own systems of referenceinfluenced by feelings, beliefs and behavior. Many problems of credibility can be solved if at least one of the parties concerned, realizes that at the basis there is only a problem of perception, the latter must investigate the matter so as to understand (King, 2015).

Verbal communication is used in everyday life, but also in human relationships within an organization. Verbal communication is to be treated as an integral part of every person's responsibility towards the people around it. 


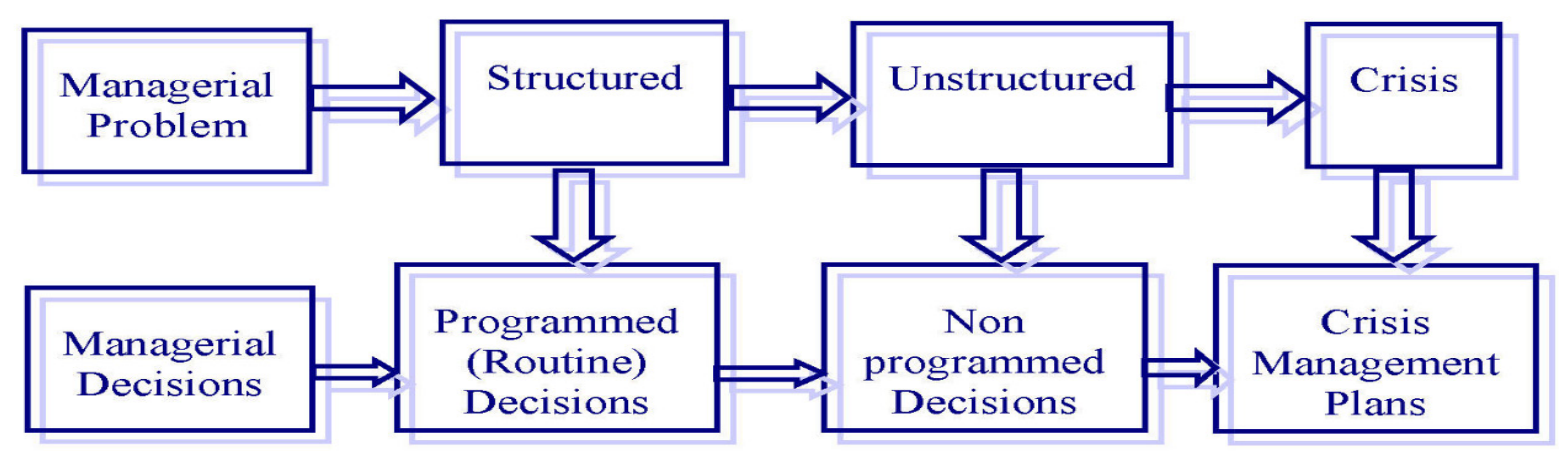

Figure no. 4 The relationship between types of managerial problems and managerial decisions (communication perspective)

(Source: Slatten, Göran \& Sander, 2011)

Language represents natural language but there are other artificial languages, such as sign-used by deaf and dumb or computer language.

The spoken language is the one that helps us communicate with our fellow human beings in different circumstances: in the family, at school, among friends, at work, etc. The way we use language to make it efficient is what makes us good communicators. In relationships, communication plays an especially important role. It depends on how we communicate the organization's mission, as part of which they can be achieved, and we have a successful career that we choose. Regardless of the place of work, no matter who is our basic professional band, which helps us take decisions, express thoughts, ideas, feelings, attitudes and so we are understood and appreciated.

To communicate ideas or feelings, we use sounds and symbols, with a generally accepted sense, which are called words. Effective communication requires skills, and their development requires practice. Wanting to express both content and intention, we are learning the language of logic and emotion-the latter being by far the most powerful and most motivating effect. We listen with our eyes first, and with our heart and only then with the ears. We seek to understand the intent of communication without prejudice. Allowing extra time and patience, trying to understand and expressing our heartfelt feelings, we present the standpoint of starting to demonstrate a clear understanding of other points of view. Communication is more a matter of trust and acceptance of others, their feelings and ideas that are different and that, from their point of view, have the same intellect (Ruck \& Welch, 2012).

From a theoretical point of view, motivation and performance are two separate concepts. Managers are interested first in their employees to attain the company's important professional objectives. It focuses on concrete results, quality and low costs. Successful completion of these targets is the result of a series of factors, which may include: effort, time and the effective engagement of people.

The effectiveness of the decisions depends on the quality and dedication of the people, and is achieved by dedication and involvement. The change process provides the opportunity to use two-thirds of our energy on reducing restrictive forces and a third on the driving forces of growth. Because each situation is different, we have to study the restrictive nature of the forces and try turning as more of these into driving forces. Involving him and others, some of the driving forces that already exist in normal people can be found here. When the proposed driving forces synchronize with the internal motivations and impulses of team members, we have a team that solves the problems together. 


\section{Organizational Culture and Communication}

The culture in which confidence is created by high upright people (who make promises to them and to others, and keep them), mature (balances the courage and self-respect, are able to express their ideas and feelings with courage, balanced by respect for the ideas and feelings of others) and with the mentality of abundance (we assume that there are enough resources for everyone, have a deep appreciation for other people and consider solutions that represent a third alternative have an unlimited potential). People of character are free to interact with genuine synergy and creativity, and therefore they can comfortably penetrate in the cultures where there is low confidence. In order for the members of the team to function, they must have fundamental skills in communication (the ability to understand thoroughly the others and being understood by them) and organization (ability to plan, act and do) and in resolving problems synergically (the ability to arrive at solutions that represent a third alternative). A manager can provide strategic direction and vision, can motivate and build a team based on mutual respect, which are complementary for each other, whether we are talking more about efficiency than performance, about direction and results than the methods, systems and procedures.

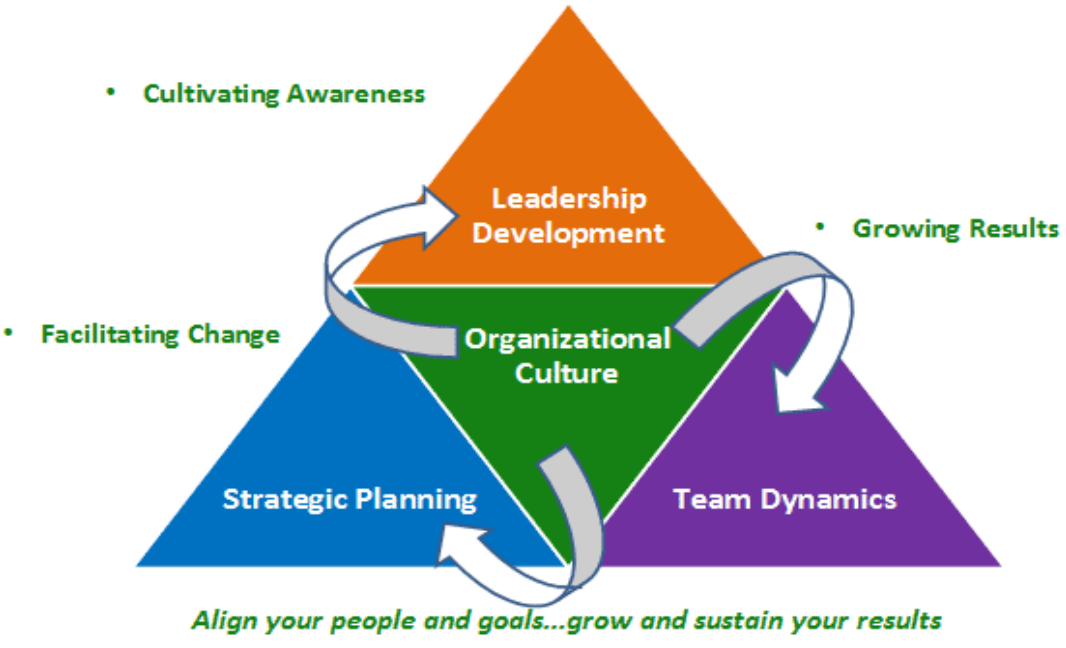

Figure no. 5 Organizational culture and communication

(Source: Kandlousi, et al, 2010)

Communication is an asset available to each organization and must be harnessed for the purpose of attaining the aims set out which are of major importance. This asset is seen, on the one hand, as a series of products, services, brands, and performance, part of respecting the objectives of the organization and on the other hand even as personality. Permanent contact with the developing organization creates connections: whether you are with your customers, suppliers, competitors, employees, or other audiences, all of which cannot exist without a communicative potential (Slatten, Göran and Sander, 2011).
Organizational communication can be divided in two directions: inside communication and outside communication. Inside communication proposes that information transmission triggers the fulfilment, by the staff of those activities, while ensuring a stimulation of the employees towards their adhesion to the objectives of the organization. Outside communication implies contacts which have the object of business through connections with suppliers, distributors, consumers, public opinion, together with the promotion of these ties.

Communication is a relational process, in which two or more parties shall 
exchange information, understand and influence each other; it is an indispensable element for the optimal operation of any human collectivities. This consists of the transmission, receipt, storage, processing and use of information. Communication is also a functional way of psycho-social interaction of people, achieved by means of symbols and meanings of the generalised social-reality, in order to obtain stability in times of changes of individual and group behavior. Effective communication requires specialized personnel in the field of communication, which deals with communication of information both internally and externally.

Internal communication aims to send, by audiences, suitable messages on which the organization wishes to serve in society. Effective internal communication will certainly result in the welding of the team working in a harmonious relationship between the employee and the employer, whereas it offers everyone the chance to get to know each other, get to know the organization's objectives in working effectively, to work, to actively participate in all activities within the Organization, to be more motivated, etc. As an instrument of internal communication, through which the Organization informs, reminds, announces projects, policies, actions, activities etc., a periodic newsletter can be used, sent via e-mail or on paper.

External communication refers to communication management strategy, which any organisation applies for the purpose of communicating messages to the general public. Any kind of information, consultation, advertisement, brochure, letter, and any form of contact between persons or things in your organization and those outside it is or should be part of the communication strategy. External communication takes into account: the identity of the organization, the organization's image, brand identity/brand, integrated campaigns. Through them, the organization/institution is known and informs all those interested in information about the activities and actions undertaken (Vidales Gonzáles, 2011).

Communication between employers and employees will be more efficient if, after a period of three months of employment, employees were asked to complete a questionnaire regarding satisfaction at work. Then, these questionnaires should be applied to all employees each year, the answers being interpreted by specialists. Another effective method of communication and, at the same time, a way to improve the performance of your employees and your organization's development would be the existence of a program with employees so that when they have something to say they can confidently go to the employer and discuss openly about any concern.

In order to achieve the desired objectives, employers need to be aware that people are less predictable and less manipulated, and managers need to work with people requesting more wisdom, energy and experience than to work with lifeless things. Therefore, the relationship between employee and employer acts as a factor of utmost motivation for the employee. Employers must not omit employee acknowledgements when required. Everyone wants to be appreciated, wants to see that his progress does not remain unnoticed, so that recognition, preferably in public, of his merits matter enormously. Being appreciated, the employee will be more motivated, more effective, more efficient, and this only requires resources of time, not necessarily money.

\section{Conclusions}

The communication process in a company is therefore an essential management tool, a particular complexity of the management system. The role of communication as a management tool is to facilitate relationships between people, to establish an environment beneficial to the internal development of the organization. 
Managers must be aware that perseverance in learning how to communicate should be a top priority for them, being the main skill which they must acquire or refine to obtain the expected results set in the company's objectives.

\section{REFERENCES}

Beattie, G. \& Ellis, A. (2014). The psychology of language and communication. London: Psychology Press.

Bodie, G. \& Crick, N. (2014). Theory of communicative action. Vol. 1: Reason and the rationalization of society. Boston, MA: Beacon Press.

Burnside-Lawry, J. (2011). The dark side of stakeholder communication: Stakeholder perceptions of ineffective organisational listening. Australian Journal of Communication, 38(1), 147-173, 149.

Frandsen, F., Johansen, W. \& Pang, A. (2013). From management consulting to strategic communication: studying the roles and functions of communication consulting. International Journal of Strategic Communication, 7(2), 81-83.

Kandlousi, N.S.A.E., et al. (2010). Organizational citizenship behavior in concern of communication satisfaction: The role of the formal and informal communication. International Journal of Business and Management, 5(10), 51-61.

King, M. (2015). Corporate blogging and microblogging: An analysis of dialogue, interactivity and engagement in organization-public communication through social media, Corporate Blogging and Microblogging PhD Thesis. Sydney: University of Technology.

Ledbetter, A.M. (2014). The past and future of technology in interpersonal communication theory and research. Communication Studies, 65(4), 456-459.

Miller, K. (2012). Organizational Communication: Approaches and Processes (6th ed.). Belmont, CA: Thomson-Wadsworth.

Ruck, K. \& Welch, M. (2012). Valuing Internal Communication; Management and Employees Perspectives. Public Relations Review, 38, 294-302.

Slatten, T., Göran, S., \& Sander S. (2011). Service Quality and Turnover Intentions as Percieved by Employees. Personnel Review, 40(2), 205-221.

Vidales Gonzáles, C. (2011). El relativismo teórico en comunicación. Entre la comunicación como principio explicativo y la comunicación como disciplina práctica. Comunicación y sociedad, (16), 11-45. 